\title{
Mean Platelet Volume in Crohn's Disease Patients Predicts Sustained Response to a 52-Week Infliximab Therapy: A Pilot Study
}

\author{
Aleksandra Sobolewska $^{1} \cdot$ Marcin Włodarczyk $^{1}$ (1) $\cdot$ Krystyna Stec-Michalska $^{1} \cdot$ \\ Jakub Fichna ${ }^{2}$ - Maria Wiśniewska-Jarosińska ${ }^{1}$
}

Received: 22 March 2015/Accepted: 18 September 2015/Published online: 6 October 2015

(C) The Author(s) 2015. This article is published with open access at Springerlink.com

\begin{abstract}
Background The loss of response to infliximab in Crohn's disease $(\mathrm{CD})$ patients is currently a major clinical problem. Recently, mean platelet volume (MPV) has been proposed as a new biomarker of CD activity. Here, we hypothesized that MPV may be used as cheap and efficient biomarker of subclinical inflammation during 52-week therapy in $\mathrm{CD}$ patients responding to infliximab induction treatment.

Aims The aim of study was to establish whether MPV at baseline and pre-infusion at week 14 are good predictors of sustained response after week 14 in CD patients undergoing 52-week infliximab therapy.

Methods A retrospective study of 30 adult CD patients who underwent a 52-week course of treatment with infliximab and achieved response at week 14 to induction treatment was performed. The association between MPV, baseline disease parameters and maintained clinical response or remission during infliximab therapy was assessed.

Results Higher MPV at week 14 was observed in CD patients with sustained response to infliximab after week 14 than in patients with loss of response $(p=0.0019)$. In patients with loss of response to maintenance infliximab treatment, lower $\triangle \mathrm{MPV}$ between baseline and week 14 was
\end{abstract}

Aleksandra Sobolewska and Marcin Włodarczyk have contributed equally to this study.

Marcin Włodarczyk

dr.mwlodarczyk@gmail.com

1 Department of Gastroenterology, Medical University of Lodz, Haller Sq. 1, 90-647 Lodz, Poland

2 Department of Biochemistry, Medical University of Lodz, Lodz, Poland calculated $(p=0.0003)$ MPV $>10.3 \mathrm{fl}$ at week 14 predicts sustained response with $67 \%$ sensitivity and $80 \%$ specificity. $\triangle \mathrm{MPV}$ between baseline and week $14>0.4 \mathrm{fl}$ predicts sustained response with $87 \%$ sensitivity and $93 \%$ specificity.

Conclusion MPV at week 14 and $\triangle \mathrm{MPV}$ between baseline and week 14 are good predictors of sustained response to infliximab maintenance treatment in $\mathrm{CD}$ patients.

Keywords Crohn's disease $\cdot$ Infliximab $\cdot$ Mean platelet volume $\cdot$ Prognosis $\cdot$ Treatment outcomes

\section{Introduction}

Crohn's disease (CD) is an inflammatory bowel disease (IBD) characterized by chronic, segmental granulomatous inflammation with periods of exacerbations and remissions, which may involve any part of the gastrointestinal (GI) tract [1]. The pathogenesis of the intestinal lesions in $\mathrm{CD}$ is not entirely understood. Elevated pro-inflammatory cytokine levels, mainly tumor necrosis factor alpha (TNF- $\alpha$ ), have strong impact on the clinical manifestations and inflammatory lesions in the intestinal wall. The main target of IBD treatment is long-term remission. Attempts have been made to find an effective treatment-biological therapy using anti-TNF- $\alpha$ antibodies, such as infliximab or adalimumab, is currently the most attractive form of treatment $[1,2]$.

The target of the anti-TNF- $\alpha$ therapy is mucosal healing and long-term clinical remission. Unfortunately, loss of response to biological agents is often observed in clinical practice, ranging from 23 to $46 \%$ after 12 months in CD patients treated with infliximab or adalimumab [3]. The mechanism underlying clinical exacerbations during 
biological treatment is not fully understood. The loss of response has been associated with the development of antibodies to anti-TNF- $\alpha$ agents and rapid drug clearance $[3,4]$. It was also postulated that some other pathways involved in $\mathrm{CD}$ development may be responsible, for example those associated with pro-inflammatory cytokines, like IL-12, IL-17, and IL-23 [5-8].

Several blood parameters have been evaluated as potential indicators of disease activity and predictors of the risk of relapse in $\mathrm{CD}$ patients during biological treatment. The most commonly used are the following: C-reactive protein (CRP), erythrocyte sedimentation rate (ESR), white blood cell (WBC) count, acid glycoprotein, platelet count, albumin with fecal (calprotectin) and serologic markers [9]. Previous studies suggested that platelets might also be involved in the pathogenesis of CD [10-12]. The mean platelet volume (MPV) has been reported to be an independent laboratory marker of clinical IBD disease activity. It has been shown that decreased MPV correlates with increased disease activity in patients with ulcerative colitis (UC) and CD [12]. It was also demonstrated that treatment with anti-TNF- $\alpha$ agents, such as infliximab, significantly improves MPV in patients with inflammatory lesions in rheumatoid arthritis (RA) [13]. In this study, we hypothesized that MPV level may be a useful biomarker of subclinical inflammation in patients with $\mathrm{CD}$ responding to infliximab induction treatment and therefore may predict maintenance or loss of response to further treatment. The aim of the study was to establish whether MPV at baseline and pre-infusion at week 14 are good predictors of sustained response or remission after week 14 in CD patients undergoing 52-week anti-TNF- $\alpha$ therapy with infliximab.

\section{Methods}

\section{Patients}

A retrospective study was conducted in 30 adult patients with CD of Caucasian origin (22 men and 8 women; mean age \pm standard deviation $32.8 \pm 8.7$ years), who were qualified for 52-week therapy with infliximab from January 2008 to March 2014 at the Department of Gastroenterology of the Medical University of Lodz, Poland. The control group comprised 15 individuals-students, staff, and patients with dyspepsia or irritable bowel syndrome, and was homogenous to the study group in terms of age, sex, and body mass index (BMI). CD was diagnosed and confirmed according to clinical, radiological, endoscopic, and histological criteria developed by the European Crohn's and Colitis Organisation (ECCO) [2]. The clinical state of each patient was classified at designated time points according to Crohn's Disease Activity Index (CDAI), which is a complex scoring system based on characteristic clinical symptoms, such as the number of liquid stools, severity of abdominal pain, general well-being, extraintestinal CD manifestations, abnormal abdominal mass, use of loperamide or opiates for diarrhea, hematocrit, and body weight $[1,2]$. The CDAI is a validated clinical/laboratory scoring system, used largely in trial settings to assess the activity of disease and the response to treatment. Despite limitations, the score has been widely used to evaluate drug efficacy in CD over a 25-year period; secondly, and perhaps more importantly, it reflects and correlates with clinical assessment and patient well-being, which is the general basis on which treatments for CD are currently justified.

Inclusion criteria for biological therapy were exacerbation of the underlying disease, CDAI over 300 , and the ineffectiveness of previously used non-biological therapies, such as mesalazine, azathioprine, and corticosteroids. All patients had endoscopic activity of intestinal lesions with ulcers, seen at colonoscopy performed just prior to initiation of infliximab therapy. All CD patients enrolled to biological therapy received induction treatment with a $5 \mathrm{mg} / \mathrm{kg}$ infliximab infusion over $2 \mathrm{~h}$ at baseline and next infusion at dose of $5 \mathrm{mg} / \mathrm{kg}$ at 2 and 6 weeks. The maintenance treatment was administered at a dose of infliximab $5 \mathrm{mg} / \mathrm{kg}$ every 8 weeks. A $1-2$ day departure from the scheme was allowed.

The CD patients enrolled in the study were in response or clinical remission at week 14 (Scheme 1); in these patients, infliximab induction had been effective and maintenance treatment began. Response to anti-TNF- $\alpha$ treatment was defined as a reduction in CDAI score by $\geq 25 \%$ and $\geq 70$ points from baseline, and maintenance of response as a sustained response at each visit after infliximab induction treatment. Clinical remission of $C D$ was defined as a CDAI score of $<150$. If response or remission was achieved at each visit after week 14, during the whole 52-week therapy, the patient was considered to have sustained response or remission in 52-week therapy. Loss of infliximab response after week 14 was defined as meeting one of the following criteria: (1) a CDAI score of $\geq 175$ and an increase in CDAI score of $\geq 35 \%$ and $\geq 70$ points for at least two following clinic visits ( $\geq 21$ days); (2) undergoing CD-related surgery; and (3) crossover from scheduled therapy to episodic retreatment. The clinical status of each patient was assessed at each visit associated with drug administration, at $0,2,6$ weeks, and every 8 week during maintenance treatment.

Current smokers, obese patients $\left(\mathrm{BMI}>25 \mathrm{~kg} / \mathrm{m}^{2}\right.$ ), patients with a history of cardiovascular disease, pulmonary and kidney disease, allergy, diabetes, lichen planus, psoriasis, atopic dermatitis and other autoimmune skin lesions and those treated with anti-inflammatory drugs 


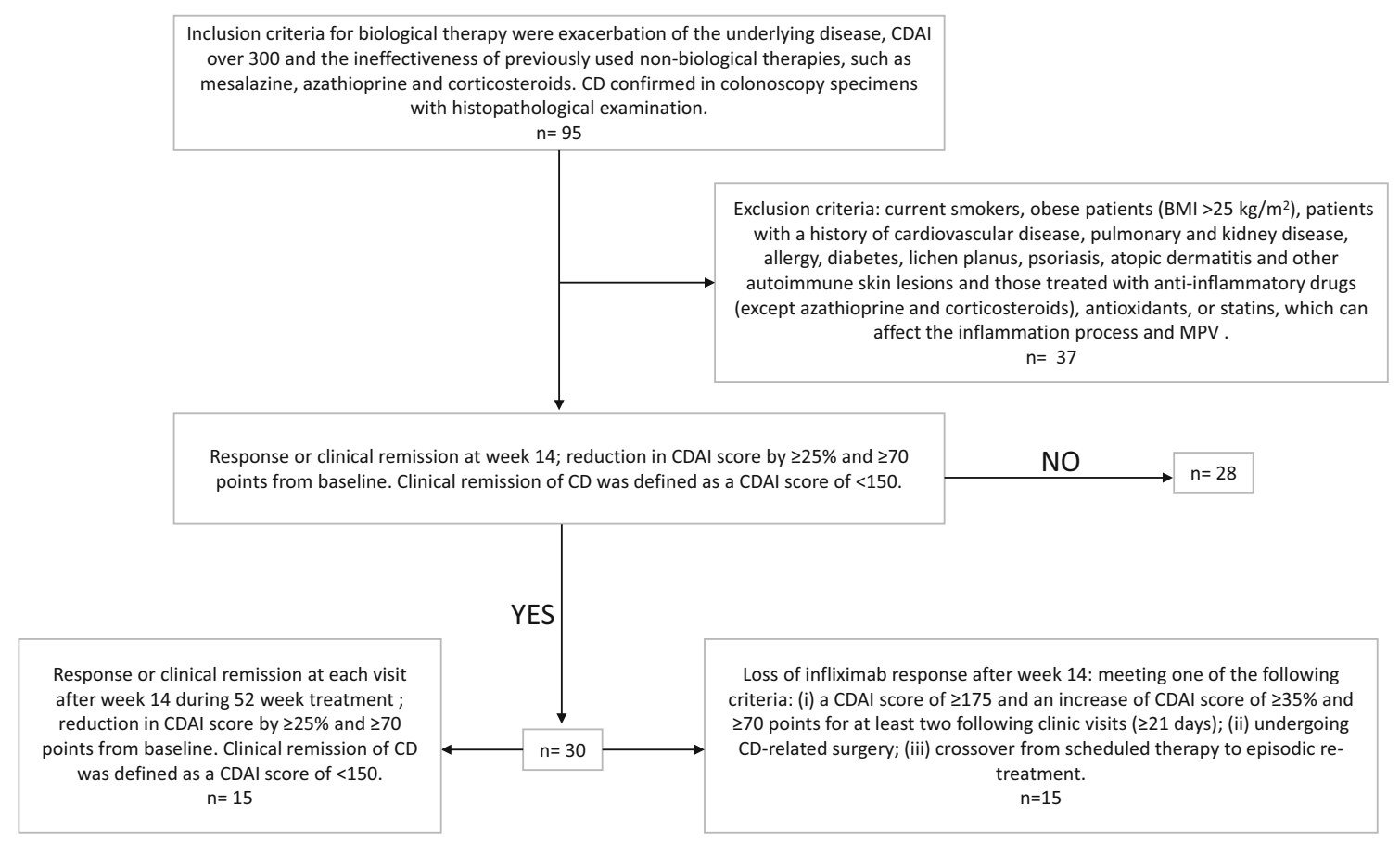

Scheme 1 The flow chart for patients' enrollment in the study

(except azathioprine and corticosteroids), antioxidants, or statins, which can affect the inflammation process and MPV [14-16], were excluded from the study.

\section{Collection of Blood Samples and Blood Analysis}

From all patients, $2 \mathrm{ml}$ venous blood was taken into standardized tubes containing ethylenediaminetetraacetic acid (EDTA) to determine MPV and white blood cell count (WBC). In CD patients, blood samples for analysis were obtained before initiation of 52-week infliximab therapy and after induction treatment at week 14. Blood analysis was performed within $2 \mathrm{~h}$ after collection using the same automatic analyser. The adult normal reference range for MPV is 7.4-10.4 $\mathrm{fl}$ and for WBC $4.5-10.3 \times 10^{9} / 1$. Also, $2 \mathrm{ml}$ blood samples were collected into serum tube and CRP was determined using automatic devices (adult normal reference range for CRP: $<0.5 \mathrm{mg} / \mathrm{dl}$ ).

\section{Statistical Analysis}

The data were analyzed using the Statistica 10.0 software (StatSoft, Inc., United States). Results were expressed as mean \pm standard deviation. Receiver operating characteristic (ROC) curves were constructed for the MPV analysis, and the areas under the ROC curves with $95 \%$ CIs were calculated and compared with each other. Optimal cutoff values for MPV, used to discriminate between patients with and without sustained response to infliximab, were calculated by ROC curves. Sensitivity, specificity, and positive and negative predictive values (PPV, NPV, respectively) of the cutoff values and association were analyzed. Shapiro-Wilk's test was used to test the distribution of the variables. Comparisons between groups were performed using the Student's $t$ test (or nonparametric Mann-Whitney $U$ test) and Chi-square test. Correlations were evaluated using the Pearson's test or Spearman's rank correlation coefficient $(r)$ test depending on normality of distribution.

A $p<0.05$ was considered significant.

\section{Ethical Considerations}

The study was conducted in accordance with the ethical principles of the 1975 Declaration of Helsinki and the study protocol was approved by the Committee of Bioethics of Medical University of Lodz.

\section{Results}

The baseline characteristics of all $30 \mathrm{CD}$ patients who underwent 52-week biological therapy with infliximab and 15 healthy controls are presented in Table 1 . Nearly $50 \%$ ( $n=15$ ) of the CD patients enrolled in the study had ileocolonic disease. Laboratory tests revealed that CD patients had significantly lower baseline MPV (10.25 \pm 0.99 vs. $11.29 \pm 1.08 \mathrm{fl} ; p=0.003)$ and hematocrit $(\mathrm{Ht})$ levels $(37.4 \pm 6.4$ vs. $43.6 \pm 11.4 \% ; p=0.025)$, as well as significantly higher platelet counts (PLT) (329 \pm 150 vs. 
Table 1 Baseline clinical characteristics and laboratory findings in the Crohn's disease (CD) patients enrolled to a 52-week infliximab therapy and healthy controls

\begin{tabular}{|c|c|c|c|}
\hline & Crohn's disease & Control group & $p^{*}$ \\
\hline Subjects, $n(\%)$ & 30 & 14 & NA \\
\hline \multicolumn{4}{|l|}{ Sex } \\
\hline Women, $n(\%)$ & $8(26.7 \%)$ & $5(35.7 \%)$ & \multirow[t]{2}{*}{0.540} \\
\hline Men, $n(\%)$ & $22(73.3 \%)$ & $9(64.3 \%)$ & \\
\hline Age, year & $32.8 \pm 8.7$ & $33.0 \pm 8.0$ & 0.934 \\
\hline BMI, $\mathrm{kg} / \mathrm{m}^{2}$ & $22.7 \pm 2.5$ & $23.1 \pm 1.5$ & 0.604 \\
\hline Duration of disease, year & $5.9 \pm 2.9$ & NA & NA \\
\hline \multicolumn{4}{|l|}{ Location of lesions, $n(\%)$} \\
\hline Ileum lesions & $2(\%)$ & \multirow[t]{4}{*}{ NA } & \multirow[t]{4}{*}{ NA } \\
\hline Colon lesions & $9(\%)$ & & \\
\hline Ileum and colon lesions & $19(\%)$ & & \\
\hline Perianal lesions & $14(\%)$ & & \\
\hline CDAI, points & $373.4 \pm 50.7$ & NA & NA \\
\hline \multicolumn{4}{|l|}{ Corticosteroid history, $n(\%)$} \\
\hline Never used & $1(3.3 \%)$ & \multirow[t]{4}{*}{ NA } & \multirow[t]{4}{*}{ NA } \\
\hline$\leq 1$ year & $3(10.0 \%)$ & & \\
\hline$>1$ to $\leq 2$ years & $11(36.7 \%)$ & & \\
\hline$>2$ years & $15(50.0 \%)$ & & \\
\hline Hematocrit, \% & $37.4 \pm 6.4$ & $43.6 \pm 11.4$ & 0.025 \\
\hline White blood cell count, $\times 10^{3} / \mu 1$ & $9.37 \pm 2.70$ & $6.11 \pm 2.59$ & $<0.001$ \\
\hline Platelet count, $\times 10^{3} / \mu 1$ & $329 \pm 150$ & $247 \pm 48$ & 0.049 \\
\hline Mean platelet volume, fl & $10.25 \pm 0.99$ & $11.29 \pm 1.08$ & 0.003 \\
\hline $\mathrm{CRP}, \mathrm{mg} / \mathrm{dl}$ & $19.7 \pm 25.3$ & $1.1 \pm 0.8$ & 0.009 \\
\hline
\end{tabular}

Data are presented as mean \pm standard deviation or number (percentage)

$B M I$ Body mass index, CDAI Crohn's Disease Activity Index, CRP C-reactive protein, NA not applicable $p^{*}$-statistical significance between $\mathrm{CD}$ patients and healthy control group $\left.247 \pm 48 \times 10^{3} / \mu \mathrm{l} ; p=0.049\right)$ compared with the healthy control group. The study showed a negative correlation of moderate strength in $\mathrm{CD}$ patients between baseline CDAI and MPV $(r=-0.522 ; p=0.003 ;$ Fig. 1$)$, and $\mathrm{Ht}$ $(r=-0.438 ; p=0.015)$. There was no significant correlation between the CDAI and CRP, WBC, and PLT levels $(r=0.267 ; p=0.153 ; r=059 ; p=0.757 ; r=0.168$; $p=0.375$; respectively). CRP levels in CD patient were significantly increased at baseline compared with healthy controls $(19.7 \pm 25.3$ vs. $1.1 \pm 0.8 ; p=0.009)$. However, seven CD patients ( $n=7 ; 23.3 \%)$ had persistent low CRP levels (CPR level under $5 \mathrm{mg} / \mathrm{dl}$ ) despite clinical and endoscopic disease activity.

In all CD patients, there was no significant association between infliximab sustained response and gender $(p=0.099)$ or age at diagnosis $(31.3 \pm 9.2$ vs. $34.2 \pm 8.6$; $p=0.385$ ) (Table 2). No significant relationship was found between location and response to infliximab $(p=0.507)$, and disease duration $(p=0.410)$ (Table 2).

Baseline MPV and week 14 MPV levels in CD patients were not influenced by perianal disease $(p=0.942$ and

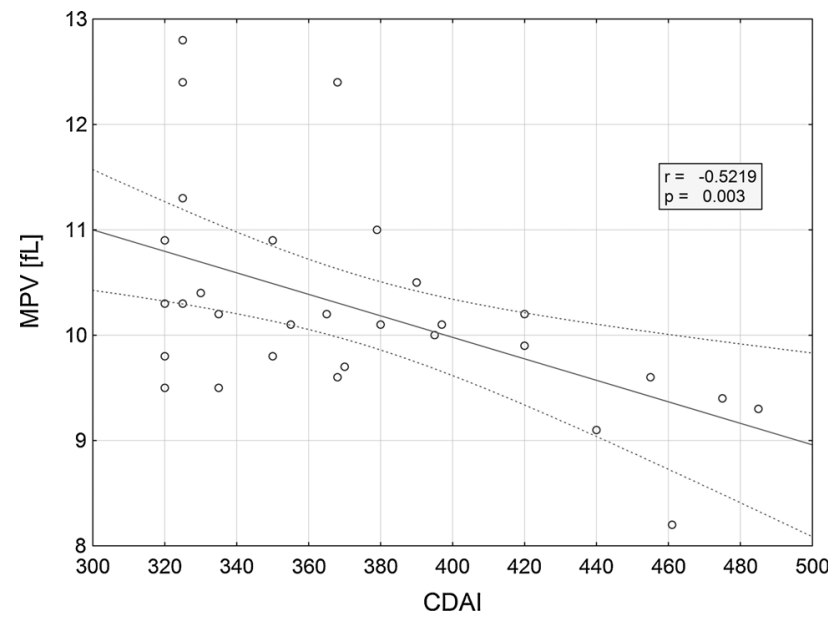

Fig. 1 Correlation between the mean platelet volume (MPV) level and Crohn's Disease Activity Index (CDAI) score $(r=-0.52$; $p=0.003$ )

$p=0.721$, respectively), disease location $(p=0.121$ and $p=0.224$, respectively), or disease duration $(p=0.131$ and $p=0.398$, respectively). 
Table 2 Baseline clinical characteristics in the Crohn's disease $(\mathrm{CD})$ patients with and without sustained response to maintenance infliximab treatment

\begin{tabular}{llll}
\hline & Sustained response & Loss of response & $p^{*}$ \\
\hline Subjects, $n(\%)$ & 15 & 15 & NA \\
Sex & & & \\
$\quad$ Women, $n(\%)$ & $2(25 \%)$ & $6(75 \%)$ & 0.099 \\
$\quad$ Men, $n(\%)$ & $13(59 \%)$ & $9(41 \%)$ & \\
Age at diagnosis, year & $31.3 \pm 9.2$ & $34.2 \pm 8.6$ & 0.385 \\
BMI, kg/m & $23.1 \pm 3.1$ & $22.4 \pm 1.9$ & 0.494 \\
Duration of disease, year & $5.4 \pm 3.1$ & $6.5 \pm 2.8$ & 0.410 \\
Location of lesions, $n(\%)$ & $1(50 \%)$ & $1(50 \%)$ & 0.510 \\
$\quad$ Ileum lesions & $3(33 \%)$ & $6(67 \%)$ & \\
Colon lesions & $11(58 \%)$ & $8(42 \%)$ & 0.423 \\
$\quad$ Ileum and colon lesions & $365.9 \pm 49.9$ & $381.0 \pm 52.0$ & \\
Baseline CDAI, points & &
\end{tabular}

Data are presented as mean \pm standard deviation or number (percentage)

$B M I$ Body mass index, CDAI Crohn's Disease Activity Index, $N A$ not applicable

$p^{*}$-statistical significance between sustained response and loss of response
In the study, only patients with $\mathrm{CD}$ who responded or achieved remission under infliximab induction treatment at week 14 were enrolled. Fifteen $(50.0 \%)$ of these patients have not reached a 1-year maintenance treatment without loss of response (short-term response): eleven (37.0\%) manifested clinical exacerbation of disease activity at 52-week maintenance treatment with infliximab (CDAI score of $\geq 175$ and an increase from the induction CDAI score of $\geq 35 \%$ and $\geq 70$ points for at least two following clinical visits), two (6.5\%) underwent surgery, and two $(6.5 \%)$ had to crossover from scheduled therapy to episodic retreatment.

The CD patients with sustained response had significantly higher MPV at week 14 compared with those who lost response to maintenance infliximab treatment $(11.31 \pm 1.16$ vs. $10.19 \pm 0.52 \mathrm{fl} ; p=0.0019$; Fig. 2$)$. Furthermore, the MPV at baseline in CD patients with sustained response was higher than in the patients who relapsed; however, the association between baseline MPV and the maintenance of response was not significant $(10.53 \pm 1.28$ vs. $9.97 \pm 0.48 \mathrm{fl} ; p=0.1187) . \Delta \mathrm{MPV}$, which signifies a change of MPV between baseline and week 14, was lower in patients with loss of response to infliximab versus patients with sustained response ( $0.227 \pm 0.392$ vs. $0.780 \pm 0.343 \mathrm{fl} ; p=0.0003$; Fig. 3$)$.

ROC curves were constructed to assign optimal cutoff values associated with sustained response to infliximab maintenance treatment. Areas under curves were 0.82 for MPV at week 14 and 0.92 for $\triangle$ MPV. The analysis showed that MPV $>10.3 \mathrm{fl}$ at week 14 predicts sustained response to infliximab treatment with $67 \%$ sensitivity and $80 \%$ specificity (Fig. 4). The negative predictive value (NPV) was $71 \%$. $\Delta$ MPV between baseline and week 14 higher than $0.4 \mathrm{fl}$

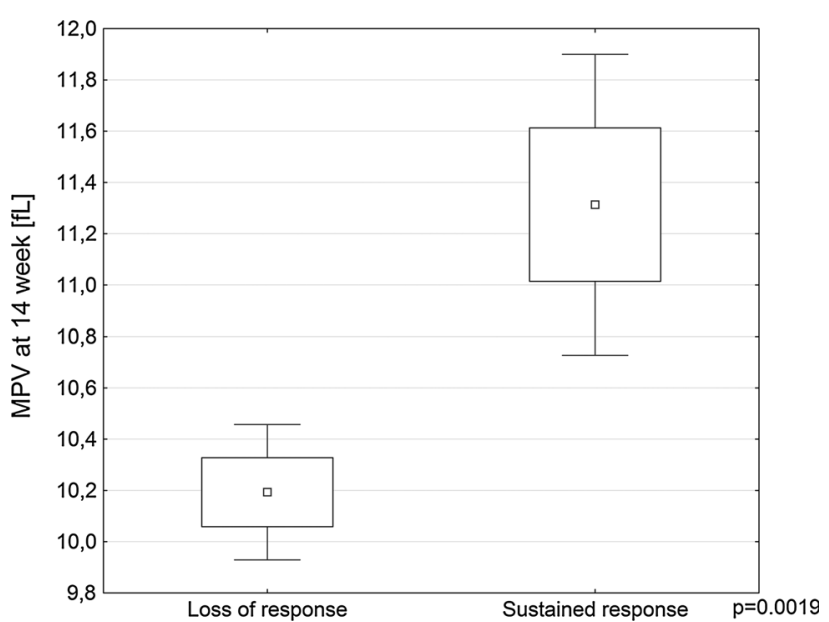

Fig. 2 Difference between mean platelet volume (MPV) levels in Crohn's disease $(\mathrm{CD})$ patients with sustained and lost response to infliximab maintenance treatment $(p=0.0019)$

predicted sustained response during 52-week treatment with $87 \%$ sensitivity and $93 \%$ specificity; the NPV was $88 \%$.

At week 14, twenty (20/30) CD patients had MPV $\geq 10.3 \mathrm{fl}$ and $65 \%$ of them (13/20) had sustained response to maintenance infliximab treatment. Ten (10/30) CD patients had $<10.3 \mathrm{fl}$ and $20 \%(2 / 10)$ had sustained response to infliximab ( $p=0.01 ;$ Fig. 5). Twenty-one (21/ 30) $\mathrm{CD}$ patients had $\geq 0.4 \mathrm{fl} \triangle \mathrm{MPV}$ (an increase in MPV value between baseline and week 14) and $71 \%$ of them (15/21) had sustained response to infliximab. None of nine (9/30) CD patients with $<0.4 \mathrm{fl} \triangle \mathrm{MPV}$ had sustained response to maintenance treatment $(p=0.0003)$. The ROC curves were also constructed for Hct, CRP, PLT, and WBC at week 14; however, the results were insignificant $(\mathrm{WBC}$ AUC $=0.524 ; \mathrm{Hct}$ 


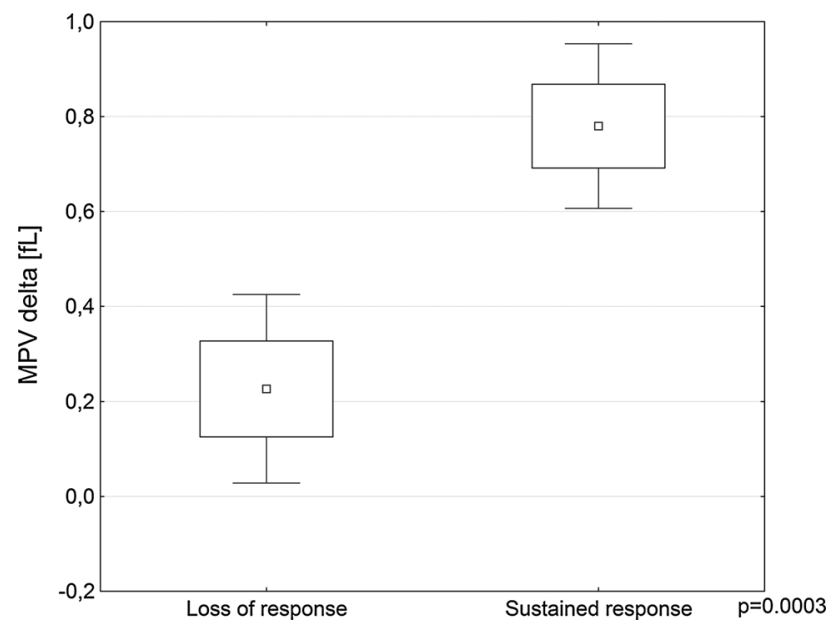

Fig. 3 Relationship between $\Delta$ mean platelet volume ( $\triangle \mathrm{MPV}$ ) levels (difference between baseline MPV levels and at week 14) in Crohn's disease $(\mathrm{CD})$ patients with sustained and lost response to infliximab maintenance treatment $(p=0.0003)$

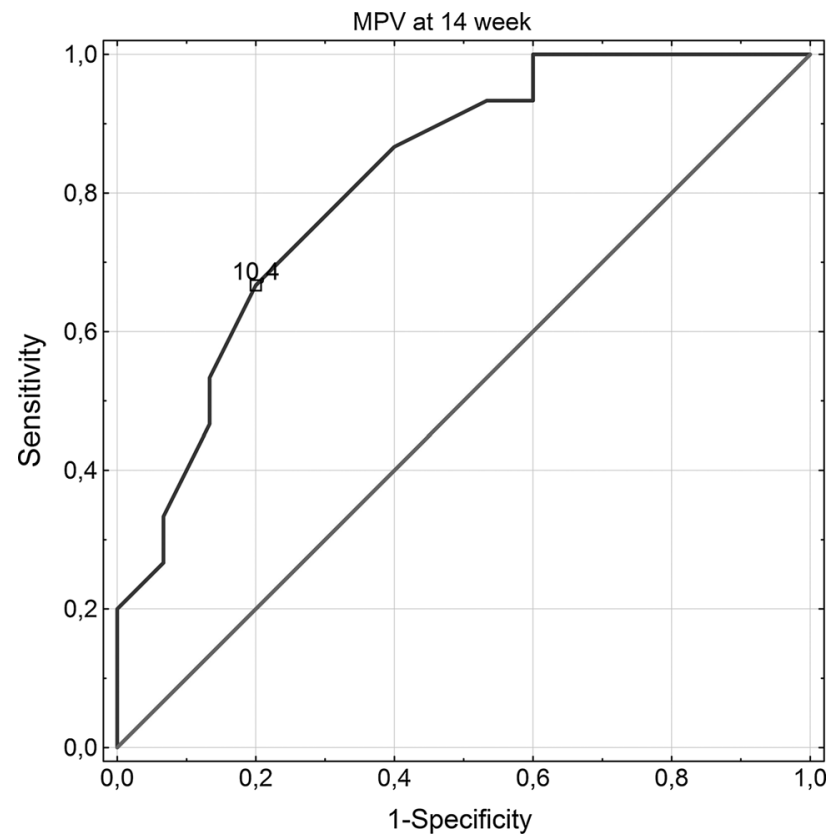

Fig. 4 Receiver operating characteristic curve for mean platelet volume (MPV) levels at week 14 and the loss of response to infliximab maintenance treatment in Crohn's disease (CD) patients during a 52-week therapy

$\mathrm{AUC}=0.542 ; \mathrm{CRP}$ AUC $=0.567 ;$ PLT $\mathrm{AUC}=0.598$; compared to MPV at week $14 \mathrm{AUC}=0.818$ ).

\section{Discussion}

We observed that higher MPV is a good indicator of a sustained response to maintenance treatment during 52-week infliximab therapy. Observation of MPV during

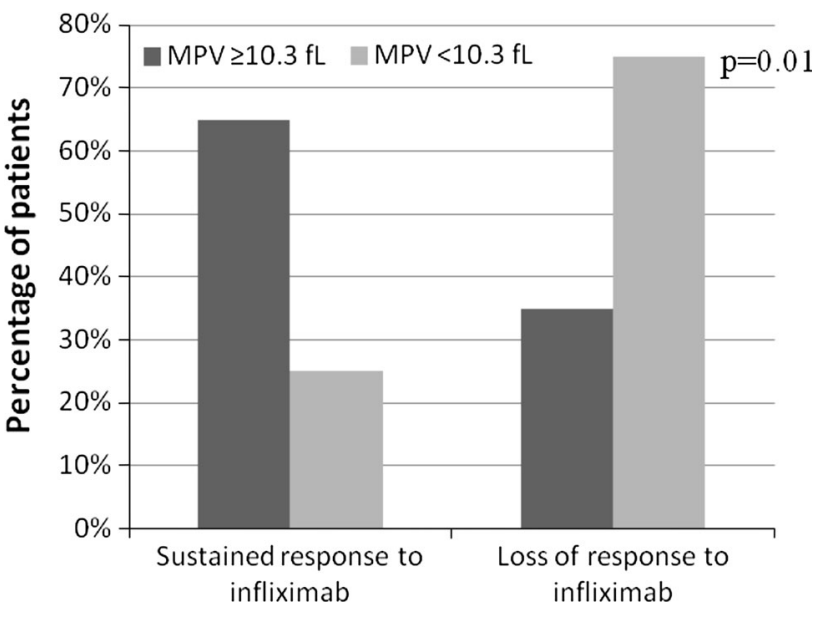

Fig. 5 Association between sustained response to infliximab 52-week maintenance therapy and mean platelet volume (MPV) levels at week 14 in Crohn's disease (CD) patients

induction treatment may become a useful tool in personalized therapy and result in better control of CD.

Infliximab, which is widely used in CD patients, effectively controls clinical symptoms, maintains remission, prevents relapses, improves quality of life, and reduces mortality. Furthermore, most CD patients respond positively to infliximab and clinical response after induction of remission is often achieved. Nevertheless, loss of response in $\mathrm{CD}$ patients under maintenance treatment with infliximab is still a common problem. Therefore, a predictor of response to anti-TNF- $\alpha$ therapy is essential in clinical practice $[4,15,16]$.

MPV is an automated measurement of the average size of platelets in whole blood that adds no extra cost or effort to a full blood count. The relationship between MPV and inflammatory process has been investigated $[4,7,10,11,13$, 17]. Currently, platelets with higher volume are considered to be involved in the infiltration of tissues with inflammation [11]. Also, $\beta$-thromboglobulin ( $\beta$-TG) and platelet factor 4 (PF4), specific proteins discharged from platelet $\alpha$-granules, have been suggested to be markers of platelet activation and influence platelet production [18]. Recent studies showed a possible relationship between MPV and some inflammatory diseases, such as acute appendicitis, chronic hepatitis B, myocardial infarction, diabetes mellitus, RA, and IBD [17, $19,20]$. For IBD, increased count and low size of platelets, as well as prothrombotic state were observed [10]. Also, increased $\beta$-TG and PF4 plasma levels have been reported [18]. Of note, a decreased MPV was evidenced as an important and useful biomarker of CD exacerbations [11]. The possible explanation for this phenomenon is that the excessive production of pro-inflammatory cytokines and acute-phase reactants may suppress the size of the platelets by interfering with megakaryopoiesis, which is followed by the release of small size platelets from the bone marrow [4]. 
Another possible explanation of the decreased size of circulating platelets in exacerbation of $\mathrm{CD}$ relates to the intensive infiltration of large platelets at sites of inflammation. It is known that large platelets are more active in releasing a variety of pro-inflammatory and thrombotic agents than smaller size platelets, and their circulating count may thus be decreased by the consumption by peripheral tissues during the acute stage of inflammation [13]. In line with these hypotheses, Gasparyan et al. [10] suggested that microaggregates and microinfarction of mesenteric vessels unveil a potential role of platelets as pro-inflammatory cells in pathogenesis of $\mathrm{CD}$. Others showed that platelets and their MPV are associated with thromboembolic risk in IBD patients and may play a role in pathogenesis of inflammation in the intestine wall. In some studies, a significant negative correlation between MPV and disease activity was observed [15], and it was suggested that a decreased MPV is an independent marker of increased disease activity in CD [21]. Similar results were demonstrated in clinical observations [20]. In our study, a significantly lower MPV was observed in $\mathrm{CD}$ patients than in healthy controls, which supports the hypothesis about the possible role of MPV in monitoring disease status. We also observed that the clinical activity of $\mathrm{CD}$, expressed on CDAI scale, at time of enrollment to infliximab therapy significantly correlates with MPV.

Anti-TNF- $\alpha$ drugs are used in the treatment of other immunological disorders, such as RA. Gasparyan et al. [13] suggested that MPV increases during anti-TNF- $\alpha$ therapy and may be a good predictor of clinical response to biological treatment in RA patients. However, to the best of our knowledge, earlier studies have not analyzed MPV as a possible predictor of sustained response to biological therapy with infliximab in $C D$ patients. Here, we observed that higher MPV at week 14 in clinical responders to infliximab induction treatment is a good indicator of a sustained response to maintenance treatment during 52-week therapy. Furthermore, CD patients with a $>0.4 \mathrm{fl}$ increase in MPV after an induction infliximab treatment (between week 0 and 14) were more likely to maintain response and remission. Since MPV $>10.3 \mathrm{fl}$ at week 14 predicts sustained response with $67 \%$ sensitivity and $80 \%$ specificity, and $\triangle \mathrm{MPV}$ (difference between baseline and week 14) higher than $0.4 \mathrm{fl}$ predicts sustained response with $87 \%$ sensitivity and $93 \%$ specificity, we suggest for the first time that the MPV could be a useful predictor in medical practice.

\section{Conclusion}

In conclusion, our study showed that MPV may be a useful biomarker predicting a sustained response in the 52-week treatment in $\mathrm{CD}$ patients receiving infliximab. We suggest that MPV, as an easily accessible biomarker, will allow clinicians to select the most appropriate individual treatment. In case of possible loss of response, physicians will be able to increase the dose of anti-TNF- $\alpha$ antibodies, change drugs or consider other treatments (i.e., antibodies against cell adhesion molecules).

This pilot study was performed on a small group of IBD patients. Further studies are warranted to confirm our observations on the predicting role of MPV and to establish the cutoff points in a larger cohort. Also, the possible application of this parameter in $\mathrm{CD}$ patients treated with other anti-TNF- $\alpha$ agents needs verification.

Acknowledgments Supported by grant from the Medical University of Lodz (\#503/1-156-04/503-01 to JF) and grants from National Science Centre (\#UMO-2013/11/B/NZ7/01301 and UMO-2014/13/B/ NZ4/01179 to JF).

\section{Compliance with ethical standards}

\section{Conflict of interest None}

Open Access This article is distributed under the terms of the Creative Commons Attribution-NonCommercial 4.0 International License (http://creativecommons.org/licenses/by-nc/4.0/), which permits any noncommercial use, distribution, and reproduction in any medium, provided you give appropriate credit to the original author(s) and the source, provide a link to the Creative Commons license, and indicate if changes were made.

\section{References}

1. Dignass A, Van AG, Lindsay JO, et al. The second European evidence-based consensus on the diagnosis and management of Crohn's disease: current management. J Crohns Colitis. 2010;4:28-62.

2. Van AG, Dignass A, Panes J, et al. The second European evidence-based consensus on the diagnosis and management of Crohn's disease: definitions and diagnosis. J Crohns Colitis. 2010;4:7-27.

3. Ben-Horin S, Chowers Y. Review article: loss of response to antiTNF treatments in Crohn's disease. Aliment Pharmacol Ther. 2011;33:987-995.

4. Cornillie F, Hanauer SB, Diamond RH, et al. Postinduction serum infliximab trough level and decrease of C-reactive protein level are associated with durable sustained response to infliximab: a retrospective analysis of the ACCENT I trial. Gut. 2014;63:1721-1727.

5. Monteleone I, Sarra M, Pallone F, Monteleone G. Th17-related cytokines in inflammatory bowel diseases: friends or foes? Curr Mol Med. 2012;12:592-597.

6. Truchetet ME, Beven L, Renaudin H, et al. Potential role of Mycoplasma hominis in interleukin (IL)-17-producing CD4+ T-cell generation via induction of IL-23 secretion by human dendritic cells. J Infect Dis. 2011;204:1796-1805.

7. Verdier J, Begue B, Cerf-Bensussan N, Ruemmele FM. Compartmentalized expression of Th1 and Th17 cytokines in pediatric inflammatory bowel diseases. Inflamm Bowel Dis. 2012;18: 1260-1266.

8. Xin L, Li Y, Soong L. Role of interleukin-1beta in activating the CD11c(high) CD. Infect Immun. 2007;75:5018-5026.

9. Mack DR, Langton C, Markowitz J, et al. Laboratory values for children with newly diagnosed inflammatory bowel disease. $P e$ diatrics. 2007;119:1113-1119. 
10. Gasparyan AY, Ayvazyan L, Mikhailidis DP, Kitas GD. Mean platelet volume: a link between thrombosis and inflammation? Curr Pharm Des. 2011;17:47-58.

11. Kapsoritakis AN, Koukourakis MI, Sfiridaki A, et al. Mean platelet volume: a useful marker of inflammatory bowel disease activity. Am J Gastroenterol. 2001;96:776-781.

12. Ozturk ZA, Dag MS, Kuyumcu ME, et al. Could platelet indices be new biomarkers for inflammatory bowel diseases? Eur Rev Med Pharmacol Sci. 2013;17:334-341.

13. Gasparyan AY, Sandoo A, Stavropoulos-Kalinoglou A, Kitas GD. Mean platelet volume in patients with rheumatoid arthritis: the effect of anti-TNF-alpha therapy. Rheumatol Int. 2010;30: $1125-1129$.

14. Bath PM, Butterworth RJ. Platelet size: measurement, physiology and vascular disease. Blood Coagul Fibrinolysis. 1996;7: 157-161.

15. Jaremo P, Sandberg-Gertzen H. Platelet density and size in inflammatory bowel disease. Thromb Haemost. 1996;75:560561.

16. Peyrin-Biroulet L, Reinisch W, Colombel JF, et al. Clinical disease activity, C-reactive protein normalisation and mucosal healing in Crohn's disease in the SONIC trial. Gut. 2014;63: $88-95$.

17. Kisacik B, Tufan A, Kalyoncu U, et al. Mean platelet volume (MPV) as an inflammatory marker in ankylosing spondylitis and rheumatoid arthritis. Joint Bone Spine. 2008;75:291-294.

18. Lecomte-Raclet L, Alemany M, Sequira-Le GA, et al. New insights into the negative regulation of hematopoiesis by chemokine platelet factor 4 and related peptides. Blood. 1998;91: 2772-2780.

19. Turhan O, Coban E, Inan D, Yalcin AN. Increased mean platelet volume in chronic hepatitis B patients with inactive disease. Med Sci Monit. 2010;16:CR202-CR205.

20. Yuksel O, Helvaci K, Basar O, et al. An overlooked indicator of disease activity in ulcerative colitis: mean platelet volume. Platelets. 2009;20:277-281.

21. Douda T, Bures J, Rejchrt S, Kopácová M, Pecka M, Malý J. Mean platelet volume (MPV) in Crohn's disease patients. Cas Lek Cesk. 2006;145:870-873. 